\title{
Selective Human Estrogen-receptor Alpha Partial Agonist TTC-352
}

National Cancer Institute

\section{Source}

National Cancer Institute. Selective Human Estrogen-receptor Alpha Partial Agonist TTC-

352. NCl Thesaurus. Code C150363.

\begin{abstract}
A benzothiophene and orally bioavailable selective human estrogen receptor alpha (ERalpha; ESR1; ERa) partial agonist (ShERPA), with potential antineoplastic activity. Upon administration, TTC-352 mimics the naturally-occurring 17beta-estradiol (E2) and targets and binds to ERa located in the nucleus. This causes translocation of ERa to extranuclear sites. Nuclear export of ERa prevents normal ER-mediated signaling and inhibits proliferation of ER-positive tumor cells. TTC-352 causes tumor reg ression of tamoxifen (TAM)-resistant (TR) tumor cells which often overexpress protein kinase $C$ alpha (PKCalpha; PKCa). PKCa expression is associated with poor patient survival and breast cancer aggressiveness and may predict tumor responses to E2, E2-like compounds and ShERPAs. Unlike E2 and E2-like compounds, TTC-352 does not cause endometrial proliferation.
\end{abstract}

